\title{
Effects of Fermented Mushroom of Cordyceps sinensis, Rich in Selenium, on Uterine Cervix Cancer
}

\author{
Jing Ji, ${ }^{1}$ Juan Liu, ${ }^{2}$ Haijuan Liu, ${ }^{1}$ and Yueling Wang ${ }^{1}$ \\ ${ }^{1}$ Department of Gynecology and Obstetrics, First Affiliated Hospital of Medical School, Xian Jiaotong University, \\ Xian 710061, China \\ ${ }^{2}$ Department of Obstetrics, Maternal \& Child Health Care Hospital of Shanxi Province, Xian 710003, China \\ Correspondence should be addressed to Yueling Wang; yuelingwangdo@tom.com
}

Received 26 April 2014; Accepted 8 May 2014; Published 25 May 2014

Academic Editor: Jianyou Guo

Copyright (c) 2014 Jing Ji et al. This is an open access article distributed under the Creative Commons Attribution License, which permits unrestricted use, distribution, and reproduction in any medium, provided the original work is properly cited.

The purpose of this study was to investigate the effect of fermented mushroom of Cordyceps sinensis (CS), rich in selenium (Se$\mathrm{CS}$ ), on uterine cervical cancer in mice. The methylcholanthrene- (MCA-) induced tumor model was used in this paper. After the mice were administered Se-CS, the animals showed $40 \%$ tumor incidence $(P<0.05)$. Se-CS also enhanced the immune functions. Se-CS treatment showed significant $(P<0.05-0.01)$ restoration in the level of glutathione content, lipid peroxidation, glutathione peroxidase activity, glutathione reductase activity, catalase activity, $\mathrm{Na}^{+} / \mathrm{K}^{+}$-ATPase activity, and glutathione $S$ transferase activity. This finding suggested that the concomitant use of Se and CS could be a potential therapeutic approach to improve the efficacy of therapy for uterine cervical cancer.

\section{Introduction}

Uterine cervical cancer is still the second most common cancer in women worldwide, despite the existence of effective screening methods $[1,2]$. However, the treatment causes strong side effects such as digestive symptoms (vomiting and diarrhea) and bone marrow suppression. Thus, drugs with fewer side effects and a superior effect in combination are desired.

In humans, selenium (Se) is a trace element nutrient which functions as cofactor for reduction of antioxidant enzymes such as glutathione peroxidases. Several studies have suggested a possible link between cancer and selenium deficiency [3-5]. Some reports show that selenium administered to laboratory animals at levels above dietary requirements is capable of protecting against tumor formation in the mammary glands, liver, skin, colon, stomach, oral cavity, bladder, and pancreas [6-8]. However, it is toxic if taken in excess. Exceeding the tolerable upper intake level of $400 \mathrm{mg}$ per day can lead to selenosis [9]. The present study evaluated the optimal concentration of Se, at which Se has equal efficacy but much lower toxicity. One novel selenium complex of SeCS has been designed and evaluated. Using trace element at lower doses, in combination with edible mushrooms, has been ascribed as one potent way to reduce trace elementsassociated toxicity and maintain their effect [10].

Cordyceps sinensis (CS) is a popular medicinal mushroom that has been used as a home remedy in traditional Chinese medicine for the prevention or treatment of a variety of diseases including cancer $[11,12]$. Today, CS is recognized as a dietary supplement recommended in many countries as a cancer therapeutic. However, some of the trails were not well designed and lacked appropriate controls [2]. In the current study, we investigated the potential therapeutic efficacy of Se-CS for cervical cancer. The purpose of this study was to investigate the effect of fermented mushroom of Se-CS on methylcholanthrene-induced uterine cervical cancer in mice.

\section{Materials and Methods}

2.1. Animals. This study was performed in accordance with the Guide for the Care and Use of Laboratory Animals. Care was taken to minimize discomfort, distress, and pain to the animals. 
Female Kunming strain mice were maintained at room temperature under alternating natural light/dark photoperiod and had access to standard laboratory food and fresh water ad libitum.

2.2. Sodium Selenite Solution (SS). Sodium selenite was dissolved in saline solution $(0.9 \% \mathrm{NaCl})$. An ampule was filled with $0.4 \mathrm{~mL}$ of SS and then was sterilized in a microwave oven for 3 minutes.

2.3. Se-Enriched Cordyceps sinensis (Se-CS). Se-CS was prepared according to study of Zhang et al. [9]. The only difference was that a series of $0 \mathrm{mg}, 0.1 \mathrm{mg}, 0.2 \mathrm{mg}, 0.4 \mathrm{mg}$, $0.6 \mathrm{mg}, 0.8 \mathrm{mg}$, and $1 \mathrm{mg}$ sodium selenite solutions was added to the substrate for obtaining Se-CS samples 1 (Se-0), 2 (Se0.1 ), 3 (Se-0.2), 4 (Se-0.4), 5 (Se-0.6), 6 (Se-0.8), and 7 (Se-1), respectively $[13,14]$.

2.4. The Effect of Se on Growth of CS. The mycelia were harvested at the end of fermentation; then they were centrifuged at $12,000 \mathrm{~g}$ for $10 \mathrm{~min}$ and dried to constant weight at $60^{\circ} \mathrm{C}$ for sufficient time in laboratory vacuum ovens, and the dry weight of the mycelia was then measured.

2.5. Analysis of Organic Selenium in Se-CS. Se-CS was dialyzed against distilled water for $96 \mathrm{~h}$ by changing the water every $12 \mathrm{~h}$ until no Se was detected in the dialyzing water. Thus, Se compounds left in the dialyzed sample were considered to be organic selenium. The Se content was determined using graphite furnace atomic absorption spectrophotometry introduced by Zhang et al. [9]. Briefly, 100 grams of properly homogenized, dry mycelia was placed in a vitreosil crucible overnight at $410^{\circ} \mathrm{C}-440^{\circ} \mathrm{C}$ in an electric muffle furnace, maintaining the temperature $1200^{\circ} \mathrm{C}$. The dry-ashing method destroys all of the organic materials present in the sample. The crucible containing pure ash was then taken out of the muffle furnace and kept in a desiccator [9]. Two grams of ash was digested with a mixture of hydrochloric acid and nitric acid in the ratio 1:3 [9]. The digested sample was dissolved in $50 \mathrm{~mL}$ of distilled water and used for analysis by means of an atomic absorption spectrometer (AAS-3200, Shanghai, China). The wavelength on selenium analyses was $196.0 \mathrm{~nm}$.

Se concentrations in liver and kidney were determined using atomic absorption spectrometer (AAS-3200, Shanghai, China). The standard of selenium was purchased from Anhui Star New Material Technology Co., Ltd, China. Weighed aliquots of frozen tissue were digested in 3 stages: the first using $5 \mathrm{~mL}$ mixed acids (4:1 nitric acid:perchloric acid), the second using a combination of $2 \mathrm{~mL} \mathrm{HNO}_{3}$ and $30 \%$ $\mathrm{H}_{2} \mathrm{O}_{2}$, and finally using $2 \mathrm{~mL} \mathrm{HNO}_{3}$. All digestion stages were performed at $130^{\circ} \mathrm{C}$ until the acid was completely evaporated and the residue dried before the next acid stage was started. After the third acid treatment, $1 \% \mathrm{HNO}_{3}$ was added to the digests and heated at $80^{\circ} \mathrm{C}$ for $1 \mathrm{~h}$. After cooling, the sample volume was measured and analyzed.

2.6. Tumor Induction by MCA. Murphy's string method [15] was followed for the induction of tumors in the uterine cervix of mice. Briefly, sterile double cotton thread impregnated with beeswax containing $600 \mu \mathrm{g}$ of MCA was inserted into the canal of the uterine cervix by means of laparotomy under mild ether anaesthesia. Forty-eight of these mice were allocated equally into 4 groups: MCA-induced group (Group 1), MCA and Se-0.4 group (Group 2), MCA and SS group (Group 3), and MCA and Se-0 group (Group 4). The other 12 normal mice were used as the control group (Group 5). From then on, the 5 groups of mice were administered orally saline, Se-CS-0.4, SS-0.4, Se-CS-0, and saline, respectively. Body weight of the animals was recorded initially, at fortnightly intervals and at autopsy. All animals surviving after 90 days were killed. Tumor incidences in control and experimental groups were calculated [16]. Tissue samples of thymus, spleen, liver, and kidney were dissected from the visceral tissues. After washing with saline, the tissue samples were blotted dry and weighed. The uterus tissues of the mice were dissected for the estimation of various parameters related to oxidative stress. All samples were stored at $-80^{\circ} \mathrm{C}$ for future analysis.

2.7. The Impact of Se-CS on Immune Organ. The impact of Se-CS on immune organ was evaluated based on the thymus index and spleen index [17]. The thymus or spleen index was calculated by the following formula: thymus (spleen) index = weight of thymus (spleen) (mg)/weight of mouse (g).

2.8. Biochemical Estimations. In uterus tissues, lactate dehydrogenase $(\mathrm{LDH})$ was estimated using a method described by Lum and Gambino [18]. Serum was used for the assay of glutathione (GSH) content, lipid peroxidation (LPO), glutathione peroxidase (GPx) activity, glutathione reductase (GR) activity, catalase (CAT) activity, $\mathrm{Na}^{+} / \mathrm{K}^{+}$-ATPase activity, and glutathione $S$ transferase (GST) activity by enzyme linked immunosorbent assay (ELISA) using DSL-10-1600 Active ELISA kit (Shanghai Jinma Biological Technology, Inc., China) [19-24].

2.9. Data Analysis. All data were analyzed by a one-way analysis of variance, and the differences between means were established by Duncan's multiple-range test. The data represents means and standard deviations. The significant level of $5 \%(P<0.05)$ was used as the minimum acceptable probability for the difference between the means.

\section{Results}

3.1. The Effect of Se on Growth of CS. Se can be accumulated by CS even from low external concentrations (Figure 1). But it is also known that Se interpolates into disulfide bridges of protein, causing a structural weakness that leads to selenosis [25]. The biomass of mycelia was significantly influenced by the concentration of Se in the medium (Figure 1). A lower concentration of Se stimulated noticeably the growth of mycelium as compared to medium without selenium. But it was no significant variety as the concentration of Se between $0.1-0.4 \%$. However, at $0.6 \%$ of Se the growth was clearly inhibited $(P<0.05)$. 


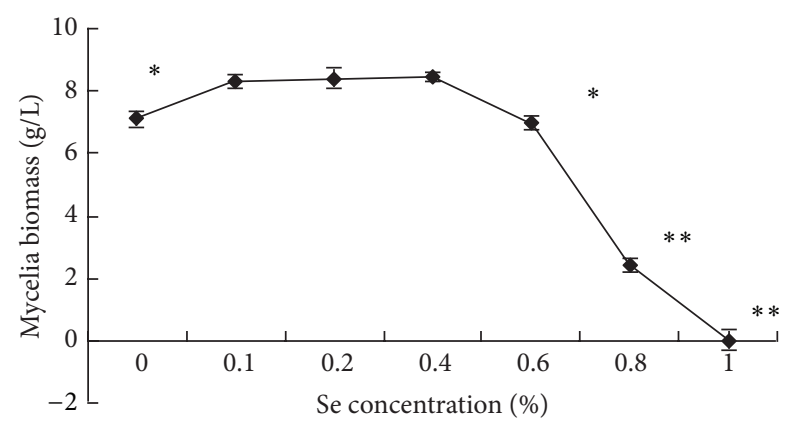

Figure 1: The effect of Se on growth of Cordyceps sinensis. The biomass of mycelia was the maximum when there was $0.4 \%$ Se in the medium. It declined rapidly when the concentration of Se exceeded $0.6 \%{ }^{*} P<0.05$ and ${ }^{* *} P<0.01$ versus $0 \mathrm{mg}$ Se.

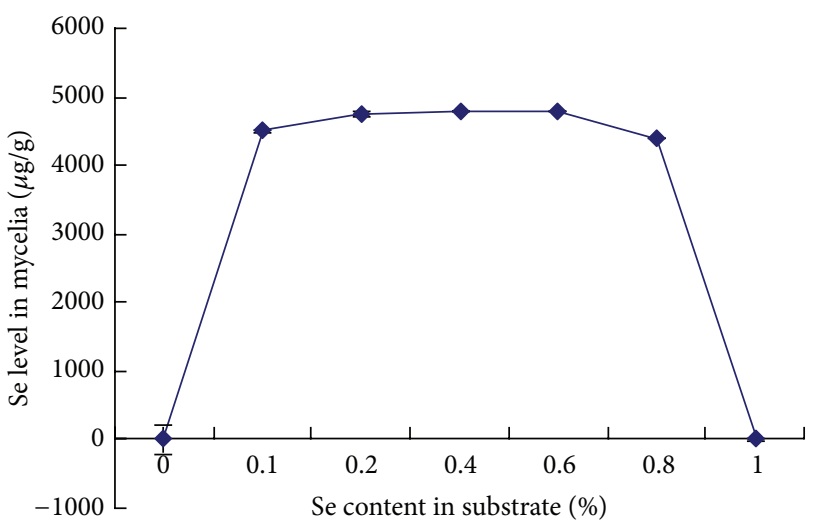

FIgure 2: The content of Se in the mycelia. The content of Se accumulated in the mycelia was $4789.26 \pm 13.0 \mu \mathrm{g} / \mathrm{g}$, when the concentration of Se in the medium was $0.4 \% . n=6$. Values are means \pm SEM.

3.2. Organic Selenium in Se-CS. The determination of selenium in mycelia obtained in the absence and in the presence of Se in medium demonstrated the incorporation of element to fungal cells (Figure 2). Apparently, there was no significant increase of selenium level in mycelia grown in $0.6 \%$ Se as compared to $0.4 \%$ Se $(P>0.05)$. Thus, we chose $0.4 \%$ Se as the optimal concentration of Se added in the liquid culture.

3.3. Effect of Se-CS on Survival of Mice Treated with MCA. The mice did not suffer from any apparent toxic effect of Se-0.4 during the observation period. Only a small number of mice died in certain groups (Table 1 ).

3.4. The Effect of Se-CS on Tumor Incidence. MCA-induced group administered orally saline showed $85.7 \%$ tumor incidence, whereas MCA and Se- 0.4 group showed $40 \%$ tumor incidence $(P<0.05)$. SS-treated group and Se-0-treated group showed $77.7 \%$ and $70 \%$ tumor incidence, respectively. Although tumor incidence in SS-treated group and Se-0treated group was lower than that of MCA-induced group, the difference was not significant $(P>0.05)$. Animals of control group showed no cervical tumor incidence (Table 2 ).
TABLE 1: Effect of SE-CS and other treatments on survival of MCAtreated mice.

\begin{tabular}{lcc}
\hline \multirow{2}{*}{ Different groups } & \multicolumn{2}{c}{ Number of mice } \\
& Initial & Final \\
\hline MCA-treated & 12 & 7 \\
MCA and Se-0.4-treated & 12 & 10 \\
MCA and Se-0-treated & 12 & 10 \\
MCA and SS-treated & 12 & 9 \\
Control group & 12 & 11 \\
\hline
\end{tabular}

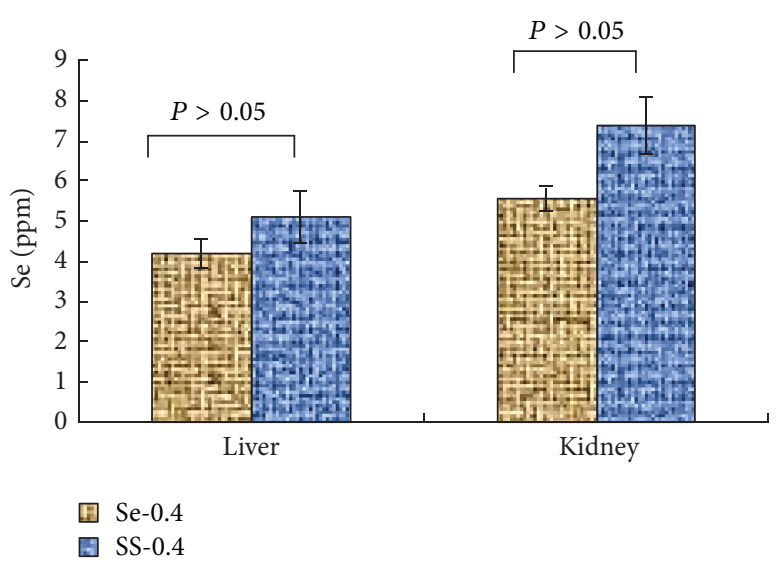

Figure 3: Se $(\mathrm{ppm})$ in animal tissues $(n=6)$. The Se $(\mathrm{ppm})$ was not significantly different between SS- 0.4 and Se- 0.4 group $(P>0.05)$.

3.5. The Effect of Se-CS on Immune Function. As shown in Table 3, compared with the Se-CS treated group, the thymus index and spleen index of mice in the MCA-treated group decreased significantly $(P<0.05)$. However, there was no significant difference between the MCA-treated group and the SS-treated group (Table 3). These results indicated that SeCS could enhance the immune functions.

3.6. Se Accumulation in Liver and Kidney. The organ masses of liver and kidney were significantly different between SS and Se-CS group $(P<0.05)$. However, there was no significant difference of organ masses of liver and kidney between the Se-0.4 and Se-0 groups $(P>0.05)$. It is implied that SS-0.4 is toxic to animals, while Se-CS is essentially nontoxic (Table 4).

The Se contents in animal tissues were measured following the studies and the results are shown in Figure 3. The Se content in tissues of Se-0.4 group was $4.21 \mathrm{ppm}$ and $5.56 \mathrm{ppm}$ (liver and kidney) while SS-0.4 groups exhibited elevated levels of Se content but not to a statistically significant degree $(P>0.05)$. It is implied that CS could reduce Se accumulation in animal tissues to a certain extent.

3.7. The Effect of Se-CS on Various Parameters Related to Oxidative Stress. $\mathrm{LDH}$ was measured to evaluate the role of antioxidative stress in the protection of Se-CS. A significant increase in the activity of $\mathrm{LDH}$ in serum was observed in MCA group, as compared to the control 
TABLE 2: Effect of SE-CS and other treatments on tumor incidence induction by MCA.

\begin{tabular}{lccc}
\hline Different groups & $\begin{array}{c}\text { Number of } \\
\text { final mice } \\
(n)\end{array}$ & $\begin{array}{c}\text { Number of mice with } \\
\text { cervical squamous cell } \\
\text { carcinoma } \\
(n)\end{array}$ & $\begin{array}{c}\text { Tumor } \\
\text { incidence } \\
(\%)\end{array}$ \\
MCA-treated & 7 & 6 & 85.7 \\
MCA and Se-0.4-treated & 10 & 7 & $40^{*}$ \\
MCA and Se-0-treated & 10 & 7 & 70 \\
MCA and SS-treated & 9 & 0 & 77.7 \\
Control group & 11 & & 0 \\
\hline
\end{tabular}

${ }^{*} P<0.05$ versus MCA-treated group.

TABLE 3: The effect of SE-CS on immune function $(n=7-11)$.

\begin{tabular}{lccc}
\hline Different groups & $\begin{array}{c}\text { Number of } \\
\text { mice } \\
(n)\end{array}$ & $\begin{array}{c}\text { Thymus } \\
\text { index }\left(\times 10^{3}\right)\end{array}$ & $\begin{array}{c}\text { Spleen } \\
\text { index }\left(\times 10^{3}\right)\end{array}$ \\
\hline MCA-treated & 7 & $1.73 \pm 0.980$ & $5.17 \pm 0.56$ \\
MCA and Se-0.4-treated & 10 & $2.78 \pm 0.06^{*}$ & $7.51 \pm 0.10^{*}$ \\
MCA and Se-0-treated & 10 & $2.56 \pm 0.03^{*}$ & $7.35 \pm 0.23^{*}$ \\
MCA and SS-treated & 9 & $2.06 \pm 0.09$ & $5.94 \pm 0.30$ \\
Control group & 11 & $2.67 \pm 0.23^{*}$ & $8.04 \pm 0.29^{*}$ \\
\hline
\end{tabular}

${ }^{*} P<0.05$ versus MCA-treated group.

TABLE 4: Effects of Se-CS on organ masses of mice $(n=7-11)$.

\begin{tabular}{lccc}
\hline Mouse group & Number of mice $(n)$ & Liver weight $(\mathrm{g})$ & Kidney weight $(\mathrm{g})$ \\
\hline Control group & 7 & $1.47 \pm 0.05^{\mathrm{a}}$ & $0.49 \pm 0.04^{\mathrm{a}}$ \\
MCA-induced group & 10 & $1.30 \pm 0.07^{\mathrm{b}}$ & $0.37 \pm 0.03^{\mathrm{b}}$ \\
MCA and SS group & 10 & $1.31 \pm 0.06^{\mathrm{b}}$ & $0.34 \pm 0.03^{\mathrm{b}}$ \\
MCA and Se-0 group & 9 & $1.48 \pm 0.07^{\mathrm{a}}$ & $0.48 \pm 0.04^{\mathrm{a}}$ \\
MCA and Se-0.4 group & 11 & $1.45 \pm 0.06^{\mathrm{a}}$ & $0.46 \pm 0.02^{\mathrm{a}}$ \\
\hline
\end{tabular}

The different letters in the same column indicate a statistical difference $(P<0.05)$.

group $(P<0.01)$, whereas Se-CS treatment significantly $(P<0.05)$ resulted in decreased serum LDH levels when compared with MCA group mice (Table 5). Concentrations of GSH were lower in MCA group than those in control group (Table 5). Se-CS produced the increase in the level of GSH $(P<0.05)$. The level of LPO content adds to the proof of the increased peroxidative damage during MCA. A significant increase $(P<0.001)$ in the content of LPO was observed in the MCA group when compared with the control group. In the Se-CS group, a significant decrease $(P<0.05)$ was seen in the level of LPO when compared with the MCA group (Table 5).

Activities of various antioxidant enzymes and $\mathrm{Na}^{+} / \mathrm{K}^{+}$ATPase of different groups have been listed in Table 6. The activity of endogenous antioxidant enzymes was decreased significantly $(P<0.01)$ in the MCA group, as compared to the control group, whereas, in the Se-CS group, Se-CS treatment showed significant $(P<0.05-0.01)$ restoration in the level of various enzymes as compared with MCA group.

\section{Discussion}

In the current study, we investigated the potential therapeutic efficacy of Se-CS for cervical cancer. Se is required in biosynthesis of important selenoenzymes. Some of them are active as catalysts for reduction of extracellular oxidants, thereby protecting cells from potential damage by these hazardous compounds. CS is recognized as a dietary supplement recommended in many countries as a cancer therapeutic. So the coeffect of CS and selenium on uterine cervix cancer was studied.

During the production of Se-CS, the biomass of mycelia was significantly influenced by the $S e$ in the medium (Figure 1). This result is consistent with the findings of another study by Han et al. [13]. The possible mechanism could be that vanadium influences the stability of cell membranes, as well as the syntheses of nucleic acids and the stability of the double helix of DNA while forming hydrogen bonds.

Survival of animals receiving Se-CS was significantly longer than the groups receiving only CS or Se. The shortest 
TABLE 5: Effect of SE-CS and other treatments on serum LDH, GSH, and LPO levels.

\begin{tabular}{lccc}
\hline Different groups $(n)$ & LDH (IU/L) & GSH (nmol/mg protein) & nmol/g protein \\
\hline Control (7) & $85.222 \pm 2.561^{* *}$ & $1.39 \pm 0.003^{* *}$ & $13.21 \pm 0.26^{* *}$ \\
MCA-induced group (10) & $181.111 \pm 3.630$ & $0.56 \pm 0.021$ & $22.20 \pm 1.01$ \\
MCA and SS group (10) & $170.121 \pm 1.220$ & $0.61 \pm 0.011$ & $22.11 \pm 2.01$ \\
MCA and Se-0 group (9) & $162.100 \pm 2.130$ & $0.79 \pm 0.031$ & $20.22 \pm 3.22$ \\
MCA and Se-0.4 group (11) & $132.222 \pm 2.201^{*}$ & $1.16 \pm 0.055^{*}$ & $16.88 \pm 0.11^{*}$ \\
\hline
\end{tabular}

Values are shown as means \pm SEM. ${ }^{*} P<0.05$ versus MCA group; ${ }^{* *} P<0.01$ versus MCA group.

TABLE 6: Effect of SE-CS and other treatments on the activity of various enzymes (nmol/g protein).

\begin{tabular}{lccccc}
\hline Different groups $(n)$ & GPx & GR & GST & CAT $^{*}$ Na $^{+}-\mathrm{ATPase}^{+}$ \\
\hline Control (7) & $16.08 \pm 1.13^{* * *}$ & $36.50 \pm 3.51^{* * *}$ & $18.01 \pm 1.12^{* *}$ & $7.88 \pm 0.13^{*}$ & $4.52 \pm 0.32^{*}$ \\
MCA-induced group (10) & $7.01 \pm 0.32$ & $20.89 \pm 2.01$ & $9.07 \pm 1.11$ & $3.20 \pm 0.13$ & $2.00 \pm 0.13$ \\
MCA and SS group (10) & $7.31 \pm 0.30$ & $21.86 \pm 1.11$ & $9.87 \pm 2.21$ & $3.88 \pm 0.83$ & $2.20 \pm 0.11$ \\
MCA and Se-0 group (9) & $7.98 \pm 0.22$ & $23.13 \pm 2.31$ & $10.07 \pm 3.22$ & $4.00 \pm 0.83$ & $3.00 \pm 0.10$ \\
MCA and Se-0.4 group (11) & $10.10 \pm 0.32^{*}$ & $25.01 \pm 2.12^{* * *}$ & $11.60 \pm 0.88^{*}$ & $4.78 \pm 0.23^{*}$ & $3.23 \pm 0.11^{*}$ \\
\hline
\end{tabular}

Values are shown as means \pm SEM. ${ }^{*} P<0.05$ versus MCA group, ${ }^{* *} P<0.01$ versus MCA group, and ${ }^{* * *} P<0.001$ versus MCA group.

survival times were observed in the no treatment group. The findings of the present study demonstrate that oral administration of Se-CS during the process of MCA-induced uterine cervix cancer results in significant reduction in the occurrence of cervical carcinomas $(P<0.05-0.01)$. CS could enhance the immune functions and reduce Se accumulation in animal tissues to a certain extent. The two agents achieve cytotoxicity through different means. It is possible that the bifunctional modulator of them inhibits tumor induction.

However, Se is also known to be toxic with a narrow range separating chronic conditions of deficiency and toxicity. The molecular toxicity of inorganic selenium was described in relation to its interaction with endogenous $-\mathrm{SH}$ groups. The animal studies have demonstrated that liver and kidney are the major target organs of Se toxicity [26]. The Se contents in animal tissues were measured following the studies. Ingestion of Se with CS reduced tissue metal accumulation, particularly for liver and kidney. At the same time, the organ masses of liver and kidney were significantly different between SS and Se-CS group $(P<0.05)$. The results indicate that Se-CS is less toxic to mice than SS.

Previous reports have shown that immunosuppression can be clearly detected in both cancer patients and tumorbearing animals, demonstrating that the immune system plays an important role in immunosurveillance against malignant cells [27]. Many attempts have been made during the past years to develop immunostimulating approaches to cancer treatment. Thymus and spleen are important immunological organs that indirectly reflect humoral immunity. Some kinds of immune inhibitors could cause thymus and spleen atrophy. Our study demonstrated that spleen and thymus indexes were significantly decreased in MCAtreated group mice. This is consistent with the conclusion that immune system plays an important role in immunosurveillance against malignant cells [27]. However, the decrease of thymus and spleen indexes caused by MCA treatment in mice was alleviated by Se-CS. It demonstrated that improved immune function achieved by Se-CS may translate into an antitumor effect. Future clinical trials are required to confirm this finding.

It has been proposed that antioxidant changes reflect an altered redox balance in several pathological states [28]. LDH was measured to evaluate the role of antioxidative stress in the protection of Se-CS. It resulted in decreased serum LDH levels when compared with MCA group mice. GSH is one of the primary endogenous antioxidant defense systems, which removes hydrogen peroxide and lipid peroxides. Decline in GSH levels could either increase or reflect oxidative status $[29,30]$. Se-CS produced the increase in the level of GSH $(P<$ $0.05)$. The large numbers of polyunsaturated fatty acids make cell membranes particularly vulnerable to lipid peroxidation. The oxidation of polyunsaturated fatty acids alters the structure of the membrane with resultant changes in fluidity and permeability. LPO can also inhibit the function of membrane bound receptors and enzymes [22]. In the Se-CS group, a significant decrease was seen in the level of LPO when compared with the MCA group. The antioxidants would be consumed in the reaction with free radicals. Therefore, the measurement of endogenous antioxidants enzymes, that is, GPx, GR, CAT, and GST, as well as $\mathrm{Na}^{+} / \mathrm{K}^{+}$-ATPase, has been performed to estimate the amount of oxidative stress. Se-CS treatment showed a significant $(P<0.05-0.01)$ restoration in the level of various enzymes as compared with MCA group. These results suggested that Se-CS on uterine cervical cancer might be directly through a lower extent of oxidative stress in MCA mice.

\section{Conclusions}

Collectively, our results indicate that Se-CS may represent a novel protective strategy against uterine cervical cancer by attenuating oxidative stress and improving immune function in MCA mice. However, the antitumor effect of Se-CS-0 and 
SS was not significant. It is implied that the antitumor effect was caused by the coeffect of CS and Se. Furthermore, our results also emphasize that Se-CS is less toxic to mice than SS. This finding suggested that the concomitant use of Se and CS could be a potential therapeutic approach to improve the efficacy of therapy for uterine cervical cancer.

\section{Conflict of Interests}

The authors declare that there is no conflict of interests.

\section{Acknowledgment}

This work was supported by the National Science Youth Foundation of China (no. 81001162).

\section{References}

[1] S. E. Waqqoner, "Cervicalcancer," The Lancet, vol. 361, no. 9376, pp. 2217-2225, 2003.

[2] J. Mahajna, N. Dotan, B. Z. Zaidman, R. D. Petrova, and S. P. Wasser, "Pharmacological values of medicinal mushrooms for prostate cancer therapy: the case of Ganoderma lucidum," Nutrition and Cancer, vol. 61, no. 1, pp. 16-26, 2009.

[3] M. Nazıroğlu, K. Yıldız, B. Tamtürk et al., "Selenium and psoriasis," Biological Trace Element Research, vol. 150, pp. 13-39, 2012.

[4] M. Nazıroǧlu, "Role of selenium on calcium signaling and oxidative stress-induced molecular pathways in epilepsy," Neurochemical Research, vol. 34, no. 12, pp. 2181-2191, 2009.

[5] G. Nilsonne, X. Sun, C. Nyström et al., "Selenite induces apoptosis in sarcomatoid malignant mesothelioma cells through oxidative stress," Free Radical Biology and Medicine, vol. 41, no. 6, pp. 874-885, 2006.

[6] K. E. Bayoummy, Cancer Principles and Practice of Oncology, V. de Vita, S. Hellman, and S. A. Rosenberg, Eds., JB Lippincott, Philadelphia, Pa, USA, 1991.

[7] M. Nazıroǧlu, A. Karaoǧlu, and A. O. Aksoy, "Selenium and high dose vitamin E administration protects cisplatin-induced oxidative damage to renal, liver and lens tissues in rats," Toxicology, vol. 195, no. 2-3, pp. 221-230, 2004.

[8] Z. Zhu, M. Kimura, Y. Itokawa, S. Nakatsu, Y. Oda, and H. Kikuchi, "Effect of selenium on malignant tumor cells of brain," Biological Trace Element Research, vol. 49, no. 1, pp. 1-7, 1995.

[9] J. Zhang, X. Wang, and T. T. Xu, "Elemental selenium at nano size (Nano-Se) as a potential chemopreventive agent with reduced risk of selenium toxicity: comparison with semethylselenocysteine in mice," Toxicological Sciences, vol. 101, no. 1, pp. 22-31, 2008.

[10] C. Han, J. Li, and Q. Hui, "Determination of trace elements in Jinqi, a traditional Chinese medicine," Biological Trace Element Research, vol. 122, no. 2, pp. 122-126, 2008.

[11] Y.-C. Kuo, C.-Y. Lin, W.-J. Tsai, C.-L. Wu, C.-F. Chen, and M.S. Shiao, "Growth inhibitors against tumor cells in Cordyceps sinensis other than cordycepin and polysaccharides," Cancer Investigation, vol. 12, no. 6, pp. 611-615, 1994.

[12] J. W. Bok, L. Lermer, J. Chilton, H. G. Klingeman, and G. H. $\mathrm{N}$. Towers, "Antitumor sterols from the mycelia of Cordyceps sinensis," Phytochemistry, vol. 51, no. 7, pp. 891-898, 1999.
[13] C. Han, B. Cui, and Y. Wang, "Vanadium uptake by biomass of coprinus comatus and their effect on hyperglycemic mice," Biological Trace Element Research, vol. 124, no. 1, pp. 35-39, 2008.

[14] C. Han and T. Liu, "A comparison of hypoglycemic activity of three species of basidiomycetes rich in vanadium," Biological Trace Element Research, vol. 127, no. 2, pp. 177-182, 2009.

[15] E. D. Murphy, "Studies in carcinogen-induced carcinoma of the cervix in mice," The American Journal of Pathology, vol. 29, p. 608, 1953.

[16] R. Das, A. R. Rao, and P. N. Srivastava, "Modulatory influences of exogenous estrogen on MCA-induced carcinogensis in the uterine cervix of mouse," Cancer Letters, vol. 43, no. 1-2, pp. 73$77,1988$.

[17] Q. Chen, Pharmaco-Study and Research Technology of Traditional Chinese Medicine, The People Public Health Publisher, Beijing, China, 2nd edition, 2006.

[18] G. Lum and S. R. Gambino, "A comparison of serum versus heparinized plasma for routine chemistry tests," American Journal of Clinical Pathology, vol. 61, no. 1, pp. 108-113, 1974.

[19] A. Caliborne, "Catalase activity," in CRC Hand Book of Methods for Oxygen Radical Research, G. Wakd, Ed., pp. 283-294, CRC Press, Boca Raton, Fla, USA, 1985.

[20] P. Svoboda and B. Mosinger, "Catecholamines and the brain microsomal $\mathrm{Na}, \mathrm{K}$-adenosinetriphosphatase. I. Protection against lipoperoxidative damage," Biochemical Pharmacology, vol. 30, no. 5, pp. 427-432, 1981.

[21] D. J. Jollow, J. R. Mitchell, N. Zampaglione, and J. R. Gillette, "Bromobenzene induced liver necrosis. Protective role of glutathione and evidence for 3,4 bromobenzene oxide as the hepatotoxic metabolite," Pharmacology, vol. 11, no. 3, pp. 151$169,1974$.

[22] C. R. Wheeler, J. A. Salzman, N. M. Elsayed, S. T. Omaye, and D. W. Korte Jr., "Automated assays for superoxide dismutase, catalase, glutathione peroxidase, and glutathione reductase activity," Analytical Biochemistry, vol. 184, no. 2, pp. 193-199, 1980.

[23] I. Carlberg and B. Mannervik, "Purification and characterization of the flavoenzyme glutathione reductase from rat liver," The Journal of Biological Chemistry, vol. 250, no. 14, pp. 5475$5480,1975$.

[24] W. H. Habig, M. J. Pabst, and W. B. Jakoby, "Glutathione S-transferases. The first enzymatic step in mercapturic acid formation," The Journal of Biological Chemistry, vol. 249, no. 22, pp. 7130-7139, 1974.

[25] T. C. Stadtman, "Selenium biochemistry," Science, vol. 183, no. 4128, pp. 915-922, 1974.

[26] J. Zhang, H. Wang, X. Yan, and L. Zhang, "Comparison of short-term toxicity between Nano-Se and selenite in mice," Life Sciences, vol. 76, no. 10, pp. 1099-1109, 2005.

[27] E. A. Vasievich, "The suppressive tumor microenvironment: a challenge in cancer immunotherapy," Molecular Pharmaceutics, vol. 8, no. 3, pp. 635-641, 2011.

[28] G. Koçer, M. Nazıroğlu, Ö. Çelik et al., "Basic fibroblast growth factor attenuates bisphosphonate-induced oxidative injury but decreases zinc and copper levels in oral epithelium of rat," Biological Trace Element Research, vol. 153, no. 1-3, pp. 251-256, 2013. 
[29] J. T. Coyle and P. Puttfarcken, "Oxidative stress, glutamate, and neurodegenerative disorders," Science, vol. 262, no. 5134, pp. 689-695, 1993.

[30] J. S. Bains and C. A. Shaw, "Neurodegenerative disorders in humans: the role of glutathione in oxidative stress-mediated neuronal death," Brain Research Reviews, vol. 25, pp. 335-338, 1997. 


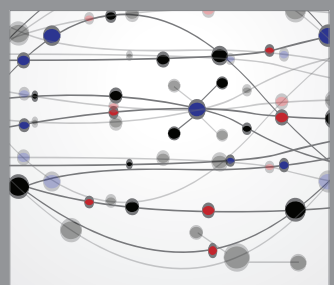

The Scientific World Journal
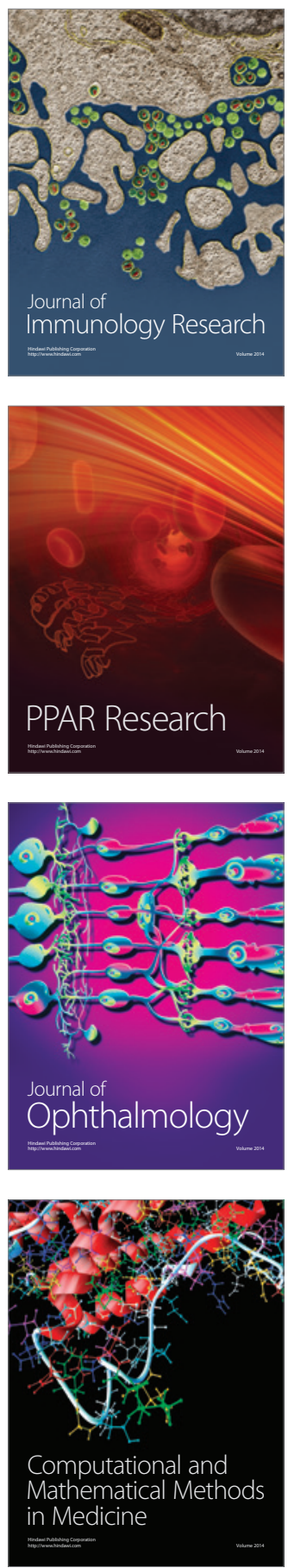

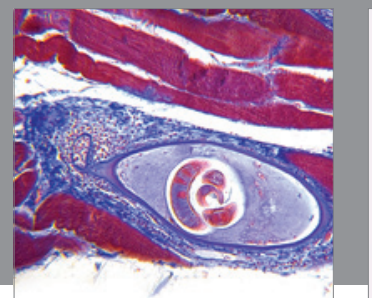

Gastroenterology

Research and Practice
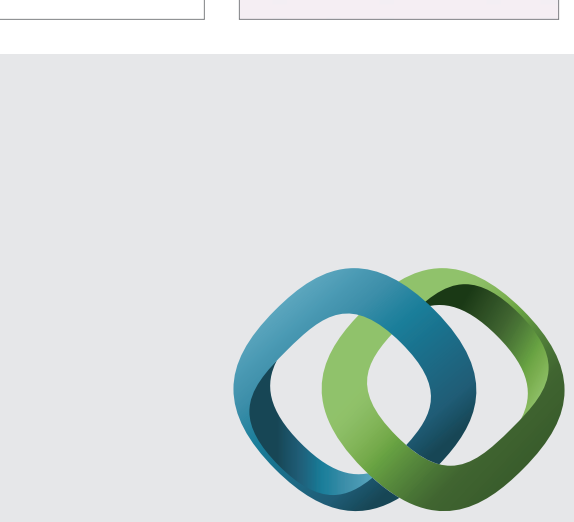

\section{Hindawi}

Submit your manuscripts at

http://www.hindawi.com
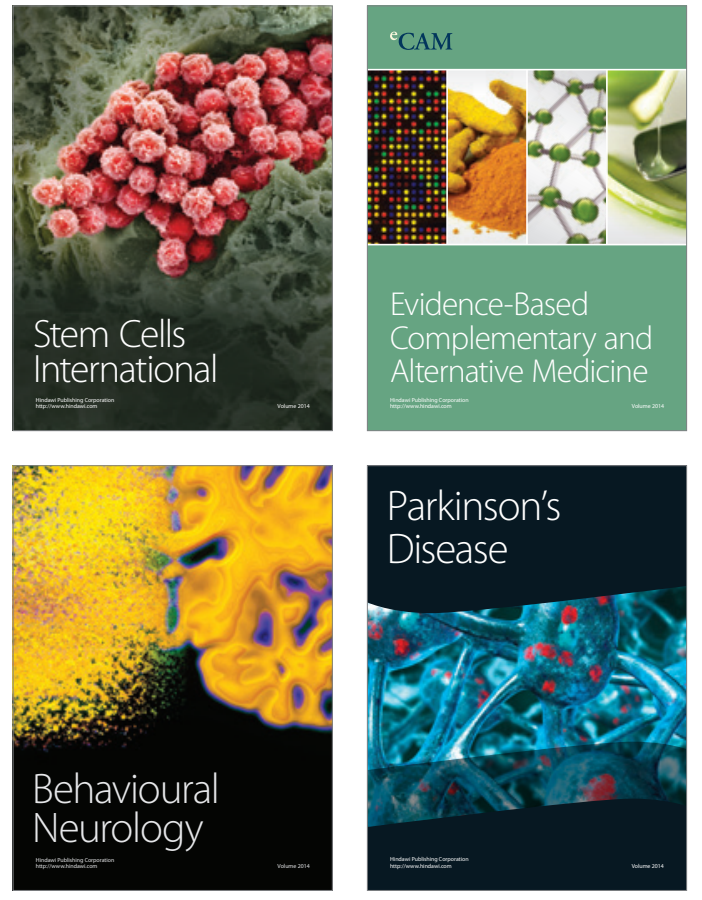
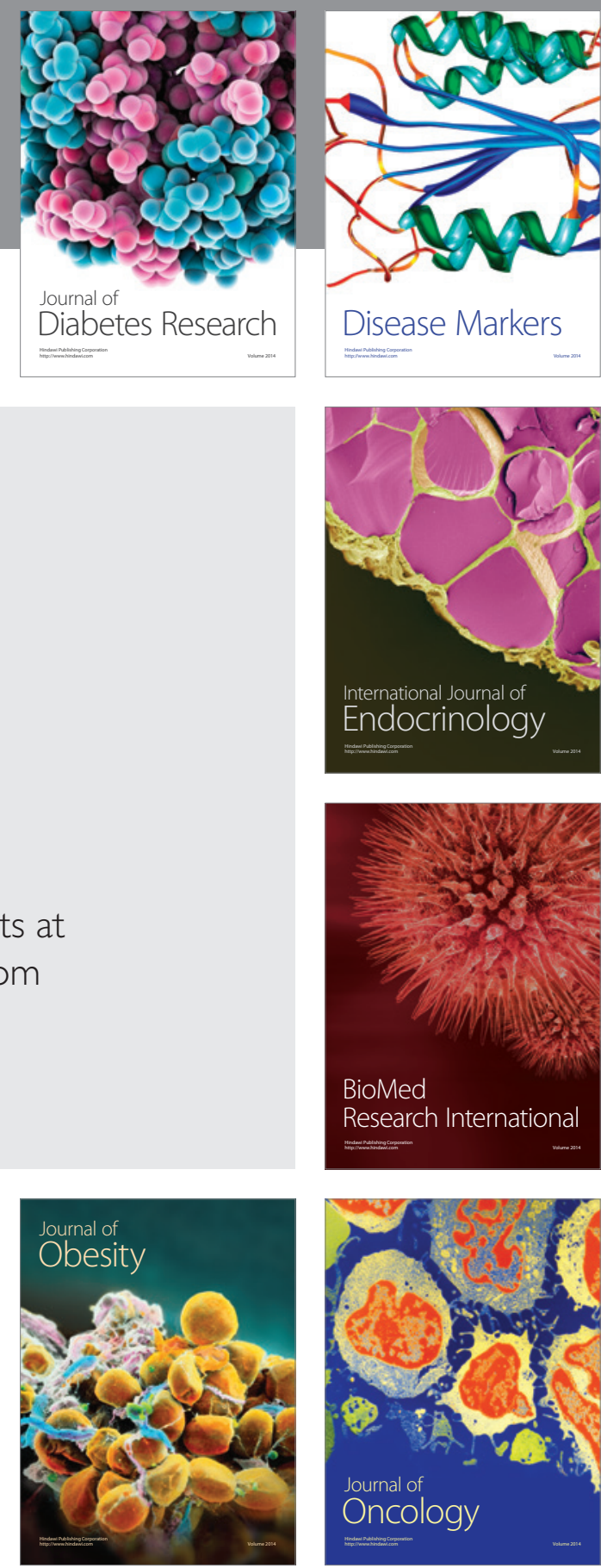

Disease Markers
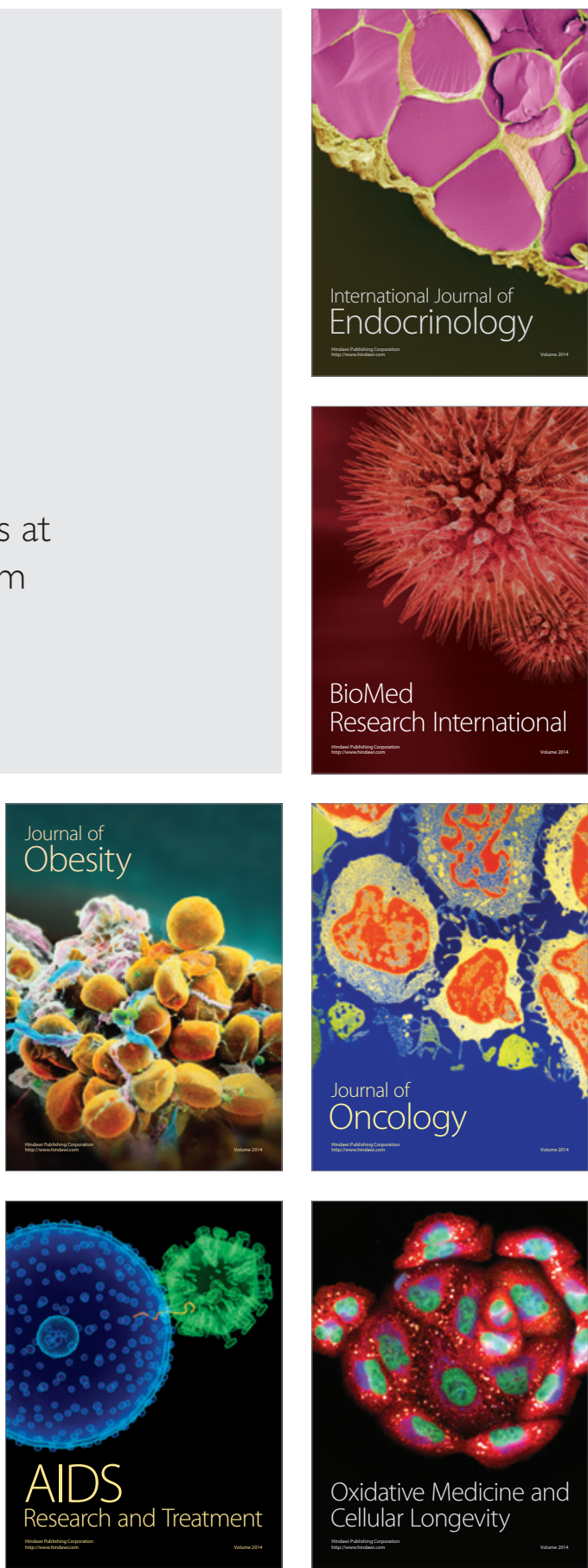